\title{
Outcome of Treatment of Haemophilus influenzae Meningitis in Children Complicated by Febrile Episodes
}

\author{
Rita Dhara Mona Badawi ${ }^{\mathrm{b}}$ Enam Al Haque ${ }^{\mathrm{b}}$ Lubna Mubasher $^{\mathrm{a}}$ \\ Zahra Oabazard $^{\mathrm{b}}$ Sameera Sadek ${ }^{\mathrm{b}}$ Mohammed Zaki ${ }^{\mathrm{c}}$ \\ a Laboratories and ${ }^{\mathrm{b}}$ Department of Paediatrics, Al-Adan Hospital, and \\ 'Department of Paediatrics, Farwania Hospital, Farwania, Kuwait
}

\section{Key Words}

Complications · Meningitis · Haemophilus

influenzae. Children

\begin{abstract}
Aim: In this retrospective study, 20 cases of Haemophilus influenzae type b (Hib) meningitis were analysed to assess the outcome of treatment. Methods: Bacteriologically proven cases of meningitis due to Hib were included in this study. The clinical and relevant laboratory data were retrieved from the hospital files. Results: Thirteen patients were treated with a combination of cefotaxime and ampicillin, 4 with cefotaxime, 2 with ceftriaxone and 1 with a combination of ampicillin and chloramphenicol. Only 9 children received concomitant dexamethasone. Nine $(45 \%)$ cases experienced permanent defervescence within 4 days of admission and were discharged from the hospital after an average stay of 10.5 days. The overall rates
\end{abstract}

\begin{tabular}{ll}
\hline KARGER & ( 1998 S. Karger AG, Basel \\
1011-7571/00/0093-0198\$17.50/0 \\
$\begin{array}{l}\text { Fax +4161306 1234 } \\
\begin{array}{l}\text { E-Mail karger@karger.ch } \\
\text { www.karger.com }\end{array}\end{array}$ & $\begin{array}{l}\text { Accessible online at: } \\
\text { www.karger.com/journals/mpp }\end{array}$
\end{tabular}

of secondary $(25 \%)$, persistent $(5 \%)$ and prolonged fever $(25 \%)$ were observed with an average number of days in hospital of 20.4, 20.0 and 22.8, respectively. Conclusion: Although there was no mortality, there is still a need for appropriate short-duration therapy which will help in bringing about a decline in febrile episodes, thereby reducing cost of management and hospital stay.

$$
\text { Copyright } \odot 2001 \text { S. Karger AG, Basel }
$$

\section{Introduction}

Haemophilus influenzae type b (Hib) has been one of the three major aetiological agents of meningitis in children beyond the neonatal period. Since the mid 1950s antimicrobial therapy in these situations has witnessed several alterations from 'triple therapy' with the combination of penicillin, chloramphenicol and sulphonamide to the present-day singledrug therapy with third-generation cephalo-

\section{Rita Dhar}

Department of Laboratories, Al-Adan Hospital, PO Box 46969 64020 Fahaheel (Kuwait)

Tel. +965394 1603, Fax +9653941724

E-Mail ritadhar50@hotmail.com 
sporins, such as cefotaxime and cetriaxone which have proven to be clinically comparable to combination therapy [1-3]. The changes were necessary due to the acquisition of resistance to various antimicrobial agents used against this pathogen. Presently, cefotaxime and ceftriaxone are being used for the treatment of Hib meningitis in many developed countries with excellent outcome [1, 3, 4], although guarantee for $100 \%$ cure rate does not exist [5]. One of the perplexing and challenging problems experienced by clinicians is the observation of continuous fever during appropriate therapy in the face of definite clinical response resulting in unnecessary addition or replacement of antibiotics and prolonged hospital stay. This report presents our experience regarding the outcome of therapy in children with meningitis due to Hib.

\section{Patients and Methods}

During the period beginning in January 1992 to July 1999, 20 children who were diagnosed as having $\mathrm{Hib}$ meningitis based on the isolation of $\mathrm{Hib}$ and/or positive latex agglutination test on cerebrospinal fluid (CSF) were included in this retrospective study. The clinical and laboratory data of these cases were retrieved from the hospital files and documented in a predesigned questionnaire.

\section{Laboratory Procedures}

It is the policy in the Paediatric Department of AlAdan Hospital to perform complete septic work-up in all patients suspected of meningitis at the time of admission. As part of this protocol CSF specimens were obtained and subjected to bacteriological, cytological and biochemical evaluation. Blood cultures and other diagnostic procedures were performed as well. Immediate examination of CSF included direct Gram stain and agglutination with latex reagents (Wellcogen, Murex, Biotech Ltd., UK) available against some of the common aetiological agents including Hib. This information along with cell counts and the biochemical profile of CSF were available within $60 \mathrm{~min}$.

The conventional method adopted for the culture of CSF involved inoculation of the specimen onto blood agar, chocolate agar, and MacConkey agar as

Outcome of Treatment of Haemophilus influenzae in Children well as thioglycollate broth. Inoculated blood agar and MacConkey agar plates were incubated aerobically at $37^{\circ} \mathrm{C}$ while chocolate agar plates were incubated in a $\mathrm{CO}_{2}$ Gaspak jar (BBL, Cockeysville, Md., USA). Colonies isolated on chocolate agar were further identified to be Hib by conventional methods [6] and tested for $\beta$-lactamase enzyme using using the chromogenic method (Cefinase, BBL). Antimicrobial susceptibility was determined by the disc-diffusion method on Mueller-Hinton chocolate agar using the Kirby-Bauer technique. The antibiotics tested included ampicillin $(10 \mu \mathrm{g})$, chloramphenicol $(30 \mu \mathrm{g})$, cefotaxime $(30 \mu \mathrm{g})$, cefuroxime $(30 \mu \mathrm{g})$, cotrimoxazole $(25 \mu \mathrm{g})$ and rifampicin $(5 \mu \mathrm{g})$.

\section{Temperature Measurement}

The temperature charts which recorded daily 4hourly rectal temperature beginning at 4 a.m. were studied in detail for each patient. The first day with temperature below $37.8^{\circ} \mathrm{C}$ for a minimum of $24 \mathrm{~h}$ was considered to be the first afebrile day. Secondary fever was defined as a temperature $\geqslant 37.8^{\circ} \mathrm{C}$ occurring after at least 1 afebrile day and recorded on at least two consecutive occasions. Fever that lasted from 5 to 9 days was termed persistent fever, while if the patient continued to be febrile beyond 9 days (i.e. $\geqslant 10$ days), it was labelled as prolonged fever. Permanent defervescence was defined as fever that settled down within 4 days of admission to the hospital and did not recur. Computerized axial tomography was done for patients with persistent or prolonged fever to rule out any subdural collection or any other abnormal finding.

\section{Antimicrobial Therapy}

Although there was some variation in the antimicrobial regimens used by three teams of paediatricians who treated these patients, the dosage of antibiotics remained the same. The doses and schedules of antibiotics used were ampicillin $200 \mathrm{mg} / \mathrm{kg} /$ day divided (div.) every $6 \mathrm{~h}$, cefotaxime $200 \mathrm{mg} / \mathrm{kg} /$ day div. every $6 \mathrm{~h}$, ceftriaxone $100 \mathrm{mg} / \mathrm{kd} /$ day div. every $24 \mathrm{~h}$, chloramphenicol $100 \mathrm{mg} / \mathrm{kg} /$ day div. every $6 \mathrm{~h}$ and rifampicin $20 \mathrm{mg} / \mathrm{kg} /$ day div. every $12 \mathrm{~h}$. Nine patients received dexamethasone in a dose of $0.6 \mathrm{mg} / \mathrm{kg} /$ day div. 6 hourly for 4 days.

\section{Follow-up}

Patients were followed up in the outpatient department at bimonthly intervals for 2 years to record improvement in the complications observed at the time of discharge or development of any late complications. 
Table 1. Outcome of treatment in relation to behaviour of fever

\begin{tabular}{|c|c|c|c|c|c|c|}
\hline \multirow[t]{2}{*}{ Antibiotic treatment } & \multirow{2}{*}{$\begin{array}{l}\text { Concomitant } \\
\text { dexamethasone } \\
\text { administration }\end{array}$} & \multicolumn{4}{|l|}{ Fever pattern } & \multirow{2}{*}{$\begin{array}{l}\text { Average } \\
\text { hospital } \\
\text { stay, days }\end{array}$} \\
\hline & & $\begin{array}{l}\text { permanent } \\
\text { defervescence }^{1}\end{array}$ & $\begin{array}{l}\text { secondary } \\
{ }^{\text {fever }^{2}}\end{array}$ & $\begin{array}{l}\text { persistent } \\
\text { fever }^{3}\end{array}$ & $\begin{array}{l}\text { prolonged } \\
\text { fever }^{4}\end{array}$ & \\
\hline \multirow{2}{*}{$\begin{array}{l}\text { Cefotaxime } \\
\qquad(\mathrm{n}=4)\end{array}$} & yes $(n=2)$ & 1 & 1 & 0 & 0 & 12.0 \\
\hline & no $(n=2)$ & 1 & 0 & 0 & 1 & 18.0 \\
\hline \multirow{2}{*}{$\begin{array}{l}\text { Ceftriaxone } \\
\quad(\mathrm{n}=2)\end{array}$} & yes $(n=1)$ & 0 & 1 & 0 & 0 & 23.0 \\
\hline & no $(n=1)$ & 1 & 0 & 0 & 0 & 10.0 \\
\hline \multirow{2}{*}{$\begin{array}{l}\text { Cefotaxime + ampicillin } \\
\quad(\mathrm{n}=13)\end{array}$} & yes $(n=6)$ & 3 & 3 & 0 & 0 & 15.8 \\
\hline & no $(n=7)$ & 2 & 0 & 1 & 4 & 19.0 \\
\hline $\begin{array}{l}\text { Ampicillin }+ \text { chloramphenicol } \\
(\mathrm{n}=1)\end{array}$ & no $(\mathrm{n}=1)$ & 1 & 0 & 0 & 0 & 10.0 \\
\hline \multirow{2}{*}{\multicolumn{2}{|c|}{$\begin{array}{l}\text { Total } \\
\text { Average hospital stay, days }\end{array}$}} & $9(45 \%)$ & $5(25 \%)$ & $1(5 \%)$ & $5(25 \%)$ & \\
\hline & & 10.5 & 20.4 & 20.0 & 22.8 & \\
\hline \multicolumn{7}{|c|}{$\mathrm{n}=$ Number of patients. } \\
\hline \multicolumn{7}{|c|}{$1 \quad$ Fever for $\leq 4$ days after initiation of therapy. } \\
\hline \multicolumn{7}{|c|}{2 Fever after at least 1 afebrile day. } \\
\hline \multicolumn{7}{|c|}{ Fever for 5-9 days. } \\
\hline \multicolumn{7}{|l|}{ Fever for $\geq 10$ days. } \\
\hline
\end{tabular}

\section{Results}

There were 12 males and 8 females; ages ranged from 2 to 48 months (median $=8.50$ ). The laboratory examination of CSF revealed that the direct smear was positive for gramnegative coccobacilli in $60 \%$, whereas latex agglutination and culture for Hib were positive in 100 and $55 \%$ of cases, respectively. In 7 patients the diagnosis was established on the basis of positive agglutination of CSF alone (4 patients had concomitant blood cultures positive for Hib as well).

Nothing remarkable was found in the clinical presentation or laboratory data of the 20 children with meningitis due to Hib. However, 2 children has sustained head injury before the onset of symptoms of fever $(100 \%)$, vomiting $(75 \%)$, reluctance to feed $(30 \%)$, convulsion $(25 \%)$, and drowsiness $(20 \%)$ as seen in the remaining cases. The outcome of antimicrobial therapy with or without dexamethasone in our group of 20 patients is presented in table 1 . Of 4 patients who received cefotaxime, 2 patients who were administered concomitant dexamethasone became afebrile after $24 \mathrm{~h} ; 1$ of them developed secondary fever after 3 days, which persisted for 8 days. Rifampicin was added to the regimen and was continued for 8 days when defervescence was achieved. Of another 2 patients who did not receive dexamethasone, 1 had permanent defervescence after 3 days while the other experienced prolonged fever necessitating the addition of chloramphenicol on day 14 for 9 days. Two patients were treated with ceftriaxone and while 1 of them did not receive dexamethasone and showed permanent defervescence after 2 days, the other patient developed secondary fever after remaining afebrile for 4 days. In 13 children, treatment was initiated with ampicillin and cefotaxime. Of 
Table 2. Fever pattern and associated complications

\begin{tabular}{|c|c|c|c|c|c|c|}
\hline \multirow[t]{2}{*}{ Fever pattern ${ }^{1}$} & \multicolumn{6}{|c|}{ Complications } \\
\hline & none & $\begin{array}{l}\text { hearing } \\
\text { impairment }\end{array}$ & $\begin{array}{l}\text { developmental } \\
\text { delay }\end{array}$ & $\begin{array}{l}\text { subdural } \\
\text { effusion }\end{array}$ & $\begin{array}{l}\text { hydro- } \\
\text { cephalus }\end{array}$ & epilepsy \\
\hline $\begin{array}{l}\text { Permanent defervescence }{ }^{2} \\
\quad(n=9)\end{array}$ & 6 & 2 & 0 & -5 & 0 & 0 \\
\hline Prolonged fever ${ }^{3}(\mathrm{n}=5)$ & 0 & 2 & 0 & 3 & 2 & 0 \\
\hline Persistent fever $(\mathrm{n}=1)$ & 0 & 0 & 0 & 1 & 0 & 0 \\
\hline Secondary fever ${ }^{4}(\mathrm{n}=5)$ & 0 & 0 & 1 & 4 & 0 & 1 \\
\hline \multicolumn{7}{|l|}{$\mathrm{n}=$ Number of patients. } \\
\hline \multicolumn{7}{|l|}{ See table 1} \\
\hline \multicolumn{7}{|c|}{2 One patient lost to follow-up. } \\
\hline \multicolumn{7}{|c|}{3 One patient developed hearing impairment, subdural effusion and hydrocephalus. } \\
\hline \multicolumn{7}{|c|}{4 One patient developed subdural effusion and epilepsy. } \\
\hline \multicolumn{7}{|c|}{ CT scans not done. } \\
\hline
\end{tabular}

6 children in this group who received dexamethasone, 3 presented with permanent defervescence after an average of 1.33 days as compared to 2 of the no dexamethasone group (7 cases) who defervesced after an average of 2 days. Three patients among the former group developed secondary fever after showing clinical response for an average period of 3.5 days. While 2 children experienced 'hectic fever' with temperature rising well above $38^{\circ} \mathrm{C}$ on several occasions resulting in hospital stay of 26 and 20 days, respectively, irregular spikes of fever not exceeding $38^{\circ} \mathrm{C}$ were recorded in the 3 rd case, who received treatment in the hospital for 17 days. Among the latter group, 4 recorded prolonged fever (1$10,1-14$, and 2-17 days) and 1 had persistent fever for 5 days. In 2 patients with prolonged fever, treatment was switched to rifampicin plus chloramphenicol, achieving defervescence after 17 and 10 days, respectively, with final discharge from the hospital after 24 and 20 days, respectively. Only 1 child received a combination of ampicillin and chloramphenicol without dexamethasone, He became afe-

Outcome of Treatment of Haemophilus influenzae in Children brile after $24 \mathrm{~h}$ and was out of hospital after completing the treatment course for 10 days. The complications associated with the fever pattern observed in our patients are presented in table 2 . Six of the 9 patients $(67 \%)$ who had permanent defervescence were not found to have developed any sequelae on follow-up. Only hearing deficit was observed in 2 of the remaining patients. In contrast, all the patients who experienced febrile episodes developed neurological and/or audiologic complications.

\section{Discussion}

The third-generation cephalosporins, namely cefotaxime and ceftriaxone, have been proven to be effective in the management of childhood bacterial meningitis beyond the neonatal period $[1,5,7]$. While these agents present excellent in vitro antimicrobial activity against $\mathrm{Hib}$ with minimum inhibitory concentration (MIC) ranging from $\leq 0.002$ to $\geq 32 \mu \mathrm{g} / \mathrm{ml}, \beta$-lactamase-positive,

Med Principles Pract 2000;9:198-204 201 
ampicillin-resistant strains have increased to $\geq 30 \%$ in some centres $[1,4,8]$. Results from our laboratory corroborate these findings. With the exception of 1 case, all our patients received either of these two agents. While 17 children were treated with cefotaxime, either alone or in combination with ampicillin, 2 children received ceftriaxone (table 1). It has been shown that CSF sterilization occurs within $48 \mathrm{~h}$ of initiation of such treatment [1, $3,7]$, although this could not be proved because parents often refused to allow repeat lumbar puncture. Nine (45\%) of our patients received concomitant dexamethasone although reports on its efficacy in reducing sequelae have been conflicting [9, 10]. Fortyfour percent of these 9 cases experienced permanent defervescence as compared to $36 \%$ of the remaining 11 patients who were not administered dexamethasone. Among 9 children who were administered dexamethasone, $67 \%$ developed complications of subdural effusion, hearing impairment, fits and developmental delay, whereas $73 \%$ patients with no dexamethasone experienced similar sequelae, presenting no statistically significant difference between the two groups.

Fever, which is an important clinical parameter to monitor the recovery of a child from bacterial meningitis, often persists even after initiation of appropriate treatment [1115]. Actual quantification of fever in childhood bacterial meningitis has been shown to be a more sensitive index to determine precisely the magnitude of fever and to characterize the fever pattern [16]. Among our patients, $55 \%$ presented with an unabated pyrexial problem during treatment. The fever pattern observed in these patients is presented in table 1. An earlier study from Kuwait [15] reported overall rates of secondary (18\%) and prolonged fever $(12 \%)$ in bacterial meningitis due to various aetiological agents. But the corresponding figures calculated for Hib were 27 and $15 \%$, respectively, which are comparable to our figures of $25 \%$ for secondary and $25 \%$ for prolonged fever $(\mathrm{p}>0.05)$. Also, we find the figures of 47 and $11 \%$ reported for secondary and prolonged fevers, respectively, in Hib meningitis in an earlier study [13] similar to our findings $(\mathrm{p}>0.05)$, while keeping in line with the same definition for fevers. In yet another study which examined cases of meningitis due to different aetiological agents, overall rates of secondary (14\%), persistent $(16 \%)$ and prolonged fever $(8 \%)$ were reported [16]. However, in patients with Hib meningitis secondary fever was observed in $15 \%$ of cases and this lower frequency was attributed to short treatment policy. This may be a plausible explanation as meningitis patients at Al-Adan Hospital are treated for a minimum period of 10 days and only $45 \%$ of cases were discharged after 10.5 days (table 1). The remaining cases stayed in hospital for $\geq 20$ days probably due to hospital-acquired intercurrent infections.

Several clinical conditions have been implicated as causes for fever in such a setting. Often secondary fever is associated with nosocomial infections such as diarrhoea, upper respiratory tract infections, phlebitis, subdural effusion and drug fever [11-16].

Similar conditions are also associated with persistent and prolonged fevers with difference only in frequency of occurrence. However, more often than not the cause of fever remains undetermined as was the case in almost all our patients (only 1 case each of diarrhoea and chest infection was recorded). Although the MIC values were not determined for the tested antimicrobial agents, it has been reported that antibiotic failure is usually not considered as a reason for these fevers [3, 13]. Even though subdural effusion was diagnosed by computerized tomography of the head in 8 of 11 patients with fever (table 2), there is no evidence to show that it 
causes a rise in body temperature and is considered only an incidental finding [12]. Similar to the observations of other groups [16], we found that neurological complications were more frequently seen in patients with fever as compared to those whose hospital stay was not complicated by a febrile episode. In contrast, no correlation was observed between the pattern and duration of fever and the development of neurological abnormalities or hearing deficit at the time of discharge of the patients in earlier studies $[14,15]$. The only complication of hearing impairment was seen in one fourth of our patients who experienced permanent defervescence.

The strategy of large-scale systematic vaccination against $\mathrm{Hib}$, which began in the early 90s in the developed countries, has dramatically and effectively brought a significant decline in the incidence of meningitis in children due to this organism [17-19]. In Kuwait, vaccination with $\mathrm{Hib}$ vaccine was started in September 1997 and has helped bring down the number of cases of meningitis due to $H$. influenzae dramatically. However, the problem continues to persist in third world countries and effective measures are deemed imperative to reduce the cost of management and hospital stay [20-22]. Furthermore, since the introduction of Hib vaccine, the problem of meningitis due to other serotypes of $\mathrm{H}$. influenzae, especially type $\mathrm{f}$, has emerged [23, 24]. It is, therefore, imperative to keep strict vigilance in monitoring the changing epidemiology of invasive disease due to $H$. influen$z a e$ and its impact on population at large.

\section{Conclusion}

Despite the use of third-generation cephalosporins, which are considered optimal for the treatment of Hib meningitis, we experienced the problem of delayed fevers, and audiologic and neurologic complications. It may still seem important to formulate a shortterm appropriate therapy to overcome the aforesaid complications even when immunization against Hib is showing a decline in the number of cases of meningitis due to this organism.

\section{References}

1 Dajani AS: Cefotaxime use in pediatric infections. Diagn Microbiol Infect Dis 1995;22:105-110.

2 Klass PE, Klein JO: Therapy of bacterial sepsis, meningitis and otitis in infants and children: 1992 poll of directors of programs in pediatric infectious diseases. Pediatr Infect Dis J 1992; 11:702-705.

3 Scholz H, Hofmann T, Noack R, Edwards DJ, Stoeckel K: Prospective comparison of ceftriaxone and cefotaxime for the short-term treatment of bacterial meningitis in children. Chemotherapy 1998;44:142147.

4 Singh R, Thomas S, Kirubakaran C, Lalitha MK, Raghupathy P: Occurrence of multiple antimicrobial re- sistance among Haemophilus influenzae type by causing meningitis. Indian J Med Res 1992;95:230233.

5 Hart CA, Cuevas LE, Marzouk O, Thomson APJ, Sills J: Management of bacterial meningitis. J Antimicrob Chemother 1993;32:49-59.

6 Campos JM: Haemophilus; in Murray $P R$, Baron EJ, Pfaller MA, Tenover FC, Yolken RH (eds): Manual of Clinical Microbiology, ed 6. Washington, ASM Press, 1995, pp 556-565.

7 Lecour H, Miranda AM, Nogueira JA, Abreu C: Update on the use of cefotaxime for pediatric meningitis in Portugal. Diagn Microbiol Infect Dis 1995;22:125-127.
8 Thornsberry C, Ogilvie P, Kahn J, Mauriz Y, and the Laboratory Investigator Group: Surveillance of antimicrobial resistance in Streptococcus pneumoniae, Haemophilus influenzae, and Moraxella catarrhalis in the United States in 19961997 respiratory season. Diagn Microbiol Infect Dis 1997;29:249257.

9 Lebel MH, Freij BJ, Syrogiannopoulos GA, Chrane DF, Hoyt MJ, Stewart SM, Kennard BD, Olsen KD, McCracken GH Jr: Dexamethasone therapy for bacterial meningitis: Results of two double blind, placebo-controlled trials. N Engl J Med 1988;3319:964-971. 
10 Wald ER, Kaplan SL, Mason EO Jr, Sabo D, Ross L, Arditi M, Wiedermann BL, Barson W, Kim KS, Yogov R, et al: Dexamethasone therapy for children with bacterial meningitis: Meningitis Study Group. Pediatrics 1995;95:21-28.

11 Balagtas R, Levin S, Nelson KE, Gotoff SP: Secondary and prolonged fevers in bacterial meningitis. $\mathrm{J}$ Pediatr 1970;77:957-964.

12 Lipiridou O, Lazaridou S, Manios S: Recurrent and persistent fever in bacterial meningitis with adequate response to antimicrobial therapy. Scand J Infect Dis 1973;5:23-27.

13 Rutman DL, Wald ER: Fever in Haemophilus influenzae type by meningitis. Clin Pediatr 1981;20: 192-195.

14 Lin T-Y, Nelson JD, McCracken GH Jr: Fever during treatment for bacterial meningitis. Pediatr Infect Dis 1984;3:319-322.

15 Daoud AS, Zaki M, Al-Saleh QA: Prolonged and secondary fever in childhood bacterial meningitis. Eur J Pediatr 1989;149:114-116.
16 Anttila M, Himberg JJ, Peltola $\mathrm{H}$ : Precise quantification of fever in childhood bacterial meningitis. Clin Pediatr 1992;31:221-227.

17 Peltola H, Kilpi T, Anttila M: Rapid disappearance of $H$. influenzae type b meningitis after routine childhood immunization with conjugate vaccines. Lancet 1992;340:592-594.

18 Adams WG, Deaver KA, Cochi SL, Plikaytis BD, Zell ER, Broome CV, Wenger JD: Decline of childhood Haemophilus influenzae type $\mathrm{b}$ (Hib) disease in the Hib vaccine era. JAMA 1993;269:221-226.

19 Liptak GS, McConnochle KM, Roghmann KJ, Panzer JA: Decline of pediatric admission with Haemophilus influenzae type $\mathrm{b}$ in New York State, 1982 through 1993: Relation to immunizations. J Pediatr 1997;130:923-930.

20 Johnson AW, Mokuolu OA, Onile BA: Chloramphenicol-resistant Haemophilus influenzae meningitis in young urban Nigerian children. Acta Paediatr 1992;81:941-943.
21 St. John MA: Childhood bacterial meningitis in Barbados: Focus on Haemophilus influenzae (letter). J Trop Pediatr 1995;41:190-191.

22 Saha SK, Rikitomi N, Ruhulamin M, Watanabe K, Ahmed K, Biswas D, Hanif M, Khan WA, Islam M, Matsumoto K, Nagatake T: The increasing burden of disease in Bangladeshi children due to Haemophilus influenzae type b meningitis. Ann Trop Paediatr 1997; 17:5-8.

23 Urwin G, Krohn JA, Deaver-Robinson K, Wenger JD, Farley MM: Invasive disease due to Haemophilus influenzae serotype f: Clinical and epidemiologic characteristic in the $H$. influenzae serotype b vaccine era - the Haemophilus influenzae Study Group. Clin Infect Dis 1996;22: 1069-1076.

24 Pincus DR, Robson JM: Meningitis due to Haemophilus influenzae type f. J Paediatr Child Health 1998;34: 95-96. 